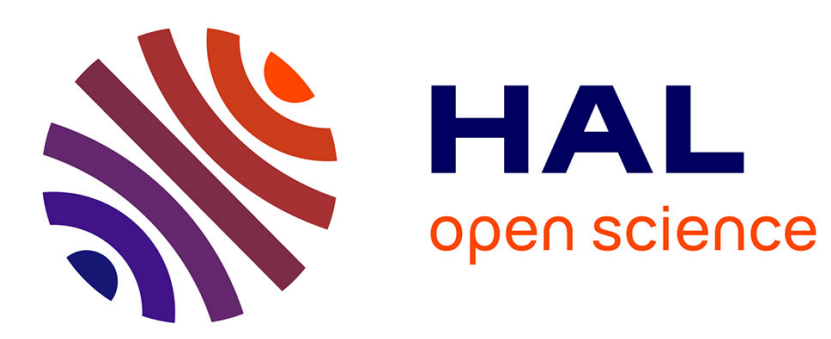

\title{
The acquisition of sociolinguistic variation: looking back and thinking ahead
}

Aurélie Nardy, Jean-Pierre Chevrot, Stéphanie Barbu

\section{To cite this version:}

Aurélie Nardy, Jean-Pierre Chevrot, Stéphanie Barbu. The acquisition of sociolinguistic variation: looking back and thinking ahead. Linguistics, 2013, 51 (2), pp.255 - 284. 10.1515/ling-2013-0011. hal-00706704v3

\section{HAL Id: hal-00706704 https://hal.science/hal-00706704v3}

Submitted on 7 Aug 2013

HAL is a multi-disciplinary open access archive for the deposit and dissemination of scientific research documents, whether they are published or not. The documents may come from teaching and research institutions in France or abroad, or from public or private research centers.
L'archive ouverte pluridisciplinaire $\mathbf{H A L}$, est destinée au dépôt et à la diffusion de documents scientifiques de niveau recherche, publiés ou non, émanant des établissements d'enseignement et de recherche français ou étrangers, des laboratoires publics ou privés. 


\title{
Nardy, A., Chevrot, J.-P. \& Barbu, S. (2013). The acquisition of sociolinguistic
}

variation: looking back and thinking ahead, Linguistics 51(2), 255-284.

\section{The acquisition of sociolinguistic variation: looking back and thinking ahead}

\author{
Aurélie NARDY ${ }^{1}$, Jean-Pierre CHEVROT ${ }^{2}$, Stéphanie BARBU ${ }^{3}$ \\ 1 LIDILEM - Laboratoire de Linguistique et Didactique des Langues Étrangères et
} Maternelles, Université de Grenoble 3, France.

${ }^{2}$ LPNC - Laboratoire de Psychologie et Neurocognition, CNRS \& Université de Grenoble, France.

${ }^{3}$ UMR 6552 Éthologie animale et humaine, CNRS \& Université de Rennes 1, France.

Contact : Aurélie Nardy

Laboratoire LIDILEM - Université de Grenoble 3

1180, Avenue Centrale - BP 25

38040 Grenoble cedex 9

Tel: (0033) 476826813

Fax: (0033) 476824395

Email: aurelie.nardy@u-grenoble3.fr

Abstract

Although developmental sociolinguistics is a relatively under-researched field, several studies have described children's use of sociolinguistic variables and some have suggested theoretical accounts for the learning mechanisms underpinning their acquisition. Taking a historical point of view, this paper aims firstly to provide an exhaustive review of the studies focused on phonological variables over the past four decades. In the second section, we then deal with three theoretical approaches to the acquisition of variation: abstract variable rule formation, case-by-case concrete learning and exemplar theory. We discuss the main assumptions of these accounts, such as the role of input frequency, abstraction and generalization processes and the construction of the relationship between linguistic and social information. Finally, in the light of this discussion and in line with the available results, we argue in favor of the usage-based theory of language acquisition (Tomasello, 2003) as a general framework including exemplar theory and explaining how children learn variable and categorical linguistic forms as well as their social use.

This research was supported by the program Apprentissages, connaissances et société proposed by the ANR (French agency for research) 


\section{Introduction}

No language is a homogeneous entity. All languages present variation at different levels: phonological, morphological, lexical, and syntactic (Coupland and Jaworski 1997). Since Labov's founding works (Labov 1972a, 1972b), sociolinguistics has described with precision the internal variation of languages. These descriptions attest to both the homogeneity and heterogeneity of linguistic knowledge, which is viewed as a system linking stability and variation. On an individual level, linguistic variation gives the speaker the opportunity to say the same thing in different ways, variants being "identical in reference or truth value, but opposed in their social and/or stylistic significance" (Labov 1972b: 271). Four decades of variationist research in adults have shown that variation is structured according to strong regularities. The usage frequency of competing variants is conditioned by intra- and extralinguistic factors. On an intralinguistic level, different studies have shown that the selection of variants depends on word frequency, grammatical constraints, phonological context, etc. (Armstrong 2001; Labov 1994; Wolfram 1969). Where extralinguistic factors are concerned, sociodemographic characteristics of speakers such as social background, gender and age are revealed to influence the choice of variants. For instance, it has been shown that speakers from higher-class backgrounds generally produce more standard variants than those from lower-class backgrounds, and that women and elders generally use more standard variants than men and the young (Labov 1972b; Trudgill 1974; Wolfram 1969). The status of individuals and the density of their ties in the local social network (neighbourhood, peer group) also affect the usage frequency of variants. The more integrated an individual is in a group, the more non standard variants he produces (Beaulieu and Cichocki 2002; Cheshire 1982; Labov 1972a; Milroy 1987). Furthermore, social characteristics being equal, the frequency of variants depends on the context of the exchange. This effect is observed at the level of macro contexts when comparing globally formal situations (classroom interaction, medical consultation) with informal situations (family meal, peer-group interaction). It also persists at the level of micro contexts i.e. successive periods during the same interaction defined according to local parameters such as changes in the topic of conversation (Coupland 1980). Another line of research on variation has established that linguistic variants are subject to social judgment. In short, so-called standard variants are associated with social prestige, a high level of education, professional ambition and efficiency, whereas so-called non standard variants are linked to social skill, and solidarity or loyalty towards the native group (Labov 
1972b; Trudgill 1975). For this reason, in observing particular interactions it can be noticed that the speaker selects specific linguistic variants in order to achieve pragmatic goals: for example, to revive a bond based on a shared identity (Gumperz 1989) or to attune the social distance to the interlocutor (Giles and Powesland 1975).

Results concerning the use of social dialects in adults are thus well established but the question of the acquisition of variable linguistic forms remains under-explored. While sociolinguistics was studying variation in adults, psycholinguistics was making considerable progress in understanding language acquisition in children. However, the two disciplines did not join forces. In the sociolinguistic domain, the question of acquisition remains a nascent field. Where psycholinguistics is concerned, the idea that the language environment is variable and structured by social factors has rarely been taken into account. And yet it is probable that the acquisition of sociolinguistic variables and their norms of usage occurs at the same time as the general development of linguistic skills (Chambers 1995). The acquisition of variation “...then, is not a by-product of the learning process, but an integral part of acquisition itself" (Roberts 2005: 153-154). This idea that the acquisition of variation is inherent to the process of acquisition itself implies taking into consideration a theoretical issue that is crucial to both psycholinguistics and sociolinguistics. This issue is explaining how children manage to build their linguistic knowledge while being part of an extremely variable, socially structured, language environment. In other words, explaining how knowledge about the social world and knowledge about language are integrated together and structure each other. What is at stake is moving towards a theory of language acquisition that includes the notion of variation and the way links between linguistic and social knowledge are constructed.

In this context, the aim of this paper is to provide an overview of research concerning children's acquisition and use of sociolinguistic variables. To be more precise, we will firstly provide a review of the studies focusing on phonological variables over the past four decades in order to specify the age at which the factors of variation intervene in development and how they evolve and interact. Secondly, we will deal with three theoretical approaches to the acquisition of variation: abstraction of variable rules, case-by-case concrete learning and exemplar theory. In the light of the results noted in the first part, we will discuss the main assumptions of these accounts before finally arguing in favor of the usage-based theory of language acquisition (Tomasello 2003) as a general framework that includes exemplar theory 
and explains how children learn linguistic forms and their social use, whether these forms are categorical or variable.

\section{Acquisition and use of sociolinguistic variables in children}

\subsection{Fischer (1958)'s precursory work}

In 1958, Fischer conducted the first variationist study of children's use of a well-known English sociolinguistic variable: the variable (-ıng) in the present participle ending. His analysis of the production of 24 children aged between 3 and 10 from a village in New England shows that the choice between [ing] (standard variant) and [in] (non standard variant) is related to gender, social background, personality (aggressive/cooperative) and mood (tense/relaxed), as well as to the formality of the conversation. Thus, girls use the standard variant more than boys, higher-SES children more than lower-SES children, and the "model" boy (academically gifted, well-behaved) more than the "typical" boy (physically strong, mischievous). More generally, children produce more standard variants in formal than in informal interviews. Although this study analyzes the productions of a sample of children of greatly differing ages, in our view these initial results are nonetheless of major importance as they have often been confirmed by subsequent studies. Fischer's pioneering approach did, however, present the flaw of being purely descriptive. In the following section we will see how, very early on, Labov (1964) suggested a developmental model in which he advanced hypotheses concerning the dynamics of the acquisition of standard English and its varieties.

\subsection{The acquisition model of standard English: Labov (1964)}

In order to observe the development of adult norms in young speakers from New York, Labov (1964) compared the performance of 58 children and adolescents, aged between 8 and 19 and divided into 5 age groups, with that of adults from their community. The performance of adults and children was estimated according to a composite index comprising both the production and evaluation of several phonological variables, without differentiating between the two. This index combines data obtained from speech produced in different situations 
(formal and informal), from subjective evaluations of variants and from an auto-evaluation test. Having calculated a percentage of results in accordance with adult norms for each age group, the author observed that as age increases children come closer to adult norms.

On the basis of these results, Labov (1964: 91-93) puts forward a developmental model for the acquisition of standard spoken English that comprises six stages. This model is the first and only attempt, to our knowledge, to offer a general theory for lifespan development of sociolinguistic competence in the field of variationist research. For the purposes of this paper, we will outline the first four stages that correspond to childhood and adolescence.

Stage 1: Basic grammar (before age 5)

This first stage corresponds to the mastering of the main grammatical rules and lexicon of spoken English and occurs under the linguistic influence of the child's parents.

Stage 2: The vernacular (age 5-12)

The child learns the use of local dialect through contact with his peer group. The linguistic influence of the peer group replaces that of his parents.

Stage 3: Social perception (early adolescence)

Although the child still uses exclusively the vernacular of his peer group, he becomes progressively aware of the social significance of this dialect as he comes into contact with other forms of speech. From the age of 14-15, children begin to display patterns of social evaluation similar to those of adults.

Stage 4: Stylistic variation (late adolescence)

The adolescent begins to learn to modify his speech using standard forms in formal situations. According to the model outlined by Labov (1964), children are monostylistic speakers until late adolescence. In this view, they are monostylistic in the dialect used in their family environment until the age of 5 , when they become monostylistic in the preferred dialect of their peer group. It is only after having understood the social value ascribed to linguistic variants (cf. stage 3) that they become able to vary their use of dialect and standard forms according to the degree of formality of the situation. However, in our view it seems surprising that certain skills from the first stage - more or less standard dialect depending on the family background - should be entirely swept aside when confronted with the peer group. Labov (1964; 1972b) does not appear to envisage the possibility of the co-existence of two dialects in children's usage, whereas he does for adult speakers, stating: “[...] there are no single-style 
speakers." (Labov 1972b: 208). Although Labov (1964) did not take social class into account as a factor in his model, he observed nonetheless that sociolinguistic norms (norms favoring the standard) were acquired at different rates according to social background. Using the same composite index as in his 1964 publication, measuring the recognition of adult prestige norms, he notes social stratification in the rate at which sociolinguistic norms are acquired: between 8 and 13, "children of upper-middle-class families start higher on the scale and show a more complete response to sociolinguistic norms than lower-middle-class children, and so on down the line." (Labov 1972b: 139). This age group corresponds to the second stage of the model (the vernacular) during which, according to Labov, children are monostylistic speakers of their peer group dialect and are as yet unaware of the social value of different variants (cf. stage 3). If social differences can be observed from this stage onwards, we would suggest the following hypotheses. Firstly, peer group vernacular is not the same for all children. Thus, the social differences observed between children from both social backgrounds could be considered the result of the different vernaculars at use within the different peer groups. Secondly, children acquire the vernacular in addition to the linguistic uses passed on from the family environment (cf. stage 1). In this case, upper-middle-class children, faced with more normative speech at home than their lower-middle-class counterparts, would display better knowledge of adult prestige norms. The latter hypothesis goes against the labovian model suggesting that young speakers are monostylistic. In this way, it suggests that, in stage 2 , the linguistic uses of the family background acquired during stage 1 could co-exist with those of the peer group. It can also be noted that, despite the social differences observed, all children whatever their social background evolve in the same "direction", i.e. towards increased recognition of prestige norms (the standard).

The acquisition model for standard English suggested by Labov $(1964,1972 b)$ thus posits that young speakers are monostylistic until adolescence. Furthermore, it supposes that awareness of the social significance of usage (cf. stage 3, around 14-15 years) precedes the ability to modify speech in formal situations. The model therefore situates the ability to modify use of standard variants according to the formality of the situation at the age of 16-17. Indirectly, Labov also implies that social differences are already in place from the age of 8 , and precede perception of the social signification of variants. Finally, the model supposes that before the age of 5 all children learn the same "basic grammar" and acquire the vernacular later upon contact with their peer group. Although Labov never explicitly returned to this model, in more recent work he considers that the variants acquired through peer-group contact 
"are built on or added to that pattern", i.e. the language pattern of their mothers (Labov 2001: 437).

Although this model has often been called into question since, it is at the origin of a whole field of research, that of the acquisition of sociolinguistic competence. In this domain, as in others, the influence of Labov's work on subsequent research remains clear, in particular where models of the acquisition of variation are concerned (see Section 3).

\subsection{General trends over the past decades}

In the following sections, we shall review research from the past four decades focusing upon phonological variables in children's linguistic development, highlighting the main results for each factor studied. The reasons behind our choice to focus only upon one level phonology - are twofold. Firstly, the vast majority of studies in children concern phonological variables. Secondly, synthesizing results concerning, for example, children's use of both phonological and morphosyntactic variables is tricky because the dynamics and factors for acquisition are likely to be different depending on the level being observed. From a historical point of view, it is important to note that studies in this field in the 1970s and 1980s approached children's production in light of established adult regularities. The 1990s saw the beginning of an increasing concern with the developmental process at work in the acquisition of variation, exploring children's linguistic uses in earlier age groups and putting forward theoretical suggestions to explain patterns of acquisition.

2.3.1. Social background. Where factors of social class in the developmental process of the variation acquisition are concerned, following the example of Chevrot et al. (2000) we shall question whether the social differences observed in the production of sociolinguistic variables are the result of an early process of transmission or a gradual process of differentiated learning of sociolinguistic usage. In other words, we shall ask whether these differences are inherited at an early age from social background due to the linguistic environment of the children, or whether they are acquired with age as development progresses.

The influence of social background upon the production of variants is the factor that has generated the most interest in research over the past 40 years. As early as 1977, Macaulay, in 
a study conducted with young speakers from Glasgow (Scotland), observed that the production of the five phonetic variables (l), (u), (a), (au) and (gs) was subject to sociolectal variation. On the basis of a study of the productions of 32 children aged 10 and aged 15 divided into four social groups, he noted the influence of social background in both age groups. The higher the social class, the more frequent the production of standard variants. This same effect was also noted in another study conducted in Scotland on two further consonantal variables $-\left(\mathrm{t}^{1}\right)$ and $\left(\mathrm{ng}^{2}\right)$ - with boys aged 11 (Reid 1978) and on the variable $(\theta)$ in Australia with children aged 10 (Martino 1982). Chevrot et al. (2000) analyzed the variable deletions in French of the final post-consonantal /R/ in children aged 6-7 and 10-12 during two tasks of differing degrees of formality (one more formal and one less formal situation). They observed an effect of social background at age 10-12, but only in the least formal situation. A study carried out with a sample of 185 French children aged between 2;3 and 6;0 from higher and lower-class backgrounds shows that the production of variable liaisons (elicited in an experimental task required naming images) is significantly more frequent in higher-class children than in lower-class children (Chevrot et al. 2011; Nardy 2008). Thus, as in adults from the same background, higher-class children produce more variable liaisons than their lower-class counterparts. More specifically, the author noted that these differences increase progressively between the ages of 2 and 6 and at age 5-6 higher-class children produce these liaisons twice as frequently as lower-class children. Using data collected by Barbu (2000), who filmed and recorded 24 children in a kindergarten with an average age of 4;9, Martin (2005) also conducted a study of variable liaisons. She found a significant correlation between three different continuous social indices ${ }^{3}$ (father's occupation, mother's occupation, father's occupation + mother's occupation) and the percentage of variable liaisons produced by the children. It should be underlined that this correlation is extremely solid because it is upheld even if the social index is considered in two discrete categories: higher versus lower class. This same early effect of social background is also noted by Díaz-Campos (2005) with 30 Venezuelan Spanish-speaking children. He observed that between 3;6 and $5 ; 11$ the children from a higher-class background produce the intervocalic /d/ more often than those from a lower-class background.

Studies that have tested the impact of social background upon the production of sociolinguistic variables all tend towards the same result: the higher the position of the family background on the social scale, the more standard variables children produce. Furthermore, 
this effect is both early and robust because it is first apparent at age 3 (Díaz-Campos 2005) and would seem to increase along with development (Chevrot et al. 2011; Nardy 2008). On the face of these results, it appears that the social differences observed in uses of sociolinguistic variables are constructed on the basis of children's linguistic environment of origin. Thus, this would mean that adult sociolectal usage is transmitted to children within the family environment that provides the requisite material for linguistic development. On this subject, it is interesting to note that, in the field of psycholinguistics, different studies have shown that from an early age the social background of the family influences the development of certain verbal aptitudes. For example, studies by Bornstein et al. (1998), Hoff et al. (2002) and Hoff $(2002,2003)$ indicate that social background influences lexical development from as early as 2 years of age. In this way, social differences in usage can be seen as constitutive of the first stages of language learning. It therefore seems essential to confirm and explore in more detail the increase in social differences as development progresses, bringing out the factors that influence these differences, such as the accumulation of input, or cultural and educational aspects.

2.3.2. Gender. In this section, we will look at developmental differences linked to gender. More specifically, we will suggest directions for exploring the question already raised concerning the influence of background: are gender differences inherited at an early stage from interactions within the family background or do they result from a gradual awareness of the social roles ascribed to girls and boys? Where gender is concerned, seemingly contradictory tendencies have been observed.

A first group of studies notes no effect of gender between ages 2 and 9 . This absence of effect is attested for the variable $(\theta)$ with 97 Australian children aged between 5;8 and 9;5 (Ingram et al. 1985), for the variable (-ıng) in the United States with 48 children divided into three age groups (4, 6 and 8 years) by Patterson (1992) and by Roberts (1994) with 17 children aged between $3 ; 2$ and 4;11. Foulkes et al. (2001) note the same absence of effect in the production of (t) in intervocalic context in Newcastle upon Tyne (England) with 24 children aged between 2 and 4 as do Smith et al. (2007) in Buckie (Scotland) with 11 children aged between $2 ; 10$ and 3;6 on the variable that they entitle 'hoose' (the alternation between the diphthong $[\Lambda \mathfrak{t}]$ and the monophtong [u:]). Finally, Chabanal (2001), in a study of 24 six- 
year old children, observed no difference according to gender on the production of liquid /R/ and $/ \mathrm{l} /$ in post-consonantal word-final context in French. This absence of a gender effect noted between the ages of 2 and 9 could argue in favor of the hypothesis of a gradual process of development that is finalized during adolescence. Docherty et al. (2006) interpret the absence of a gender effect on children's sociolinguistic development as resulting from the fact that mothers are the main source of input for both boys and girls in childhood. Thus, children of both genders firstly acquire the variants present in their mother's speech. These authors, who recorded young children in their family environment, also found that between age 2 and 4 the children, irrespective of their gender, present the same sociolinguistic regularities in the use of (t) when the variable is in an intervocalic position. This interpretation is in keeping with that of Labov (1990) who indicates that maternal variants have more chance of being transmitted, due to the mother's central role in the education of children. The later appearance of differences linked to gender could therefore emerge through contact with the peer group (Kerswill 1996).

A second group of studies shows a gender effect that corresponds to general tendencies in adults. In Edinburgh (Scotland), Romaine (1984) observes differentiation according to gender at 6,8 and 10 years of age. Young boys produce more non standard variants of the variables (gs), (l), (au), (th) and (a) than young girls. However, the author underlines that this effect does not concern all the variables in her study (the variable (lng) does not present the same regularity) and that it is not statistically significant. She reanalyzed the data from Macaulay's (1977) study, isolating the 10 year-old speakers from class III (those whose father was a lorry driver, unemployed labourer, slater or roadmender) and comparing their productions with those of her sample of children from a similar background. She observed the same tendency as in her own study for non standard variants of the variables: (gs), (l), (au), (u) and (a). If further studies confirmed such gender differences at an earlier age, it would be possible to ascribe them to differentiated transmission of variants within the child's family environment. On the basis of a study of the variable (t) in word-medial context, Foulkes et al. (2005) focused upon the type of variant used by 39 mothers with their child. They noted that mothers of boys used significantly more non standard variants than mothers of girls when addressing their child. This effect is also observed by Johnson (2003) who studied the speech of five 
mothers addressing their twins (one boy and one girl) aged from 2;5 to 3;9. Following Foulkes et al. (2005), Johnson noted that mothers selected the standard variant of the variable (t) when addressing their daughters. Foulkes et al. (2005) interpret the differences in input according to the child's gender by suggesting that the mothers are sensitive to the gender identity of their child. By using more standard forms with their daughters, mothers seem to be ensuring that the latter acquire the variants that are positively evaluated. Where the mothers of boys are concerned, these authors put forward the hypothesis that they select the variants used by adult males.

Finally, a third group of studies note a different tendency: boys seem to produce more standard variants than girls, contrary to the usual trends in adults. In a study of the word-final post-consonantal /R/ in French, Chevrot (1991) observes that at age 6-7 the gender effect does not appear autonomously but in conjunction with two other variables studied: social background and context. Indeed, only girls from a higher social background modify their use of the variable according to the situation: unexpectedly they delete /R/ more in formal situations. Furthermore, the author observes that in informal situations boys from a higher social background produce less deletion of $/ \mathrm{R} /$ than their counterparts from a lower social background. This situational reaction that Chevrot (1991) names "reversed" is clearly not in keeping with the expected result i.e. that standard variants are supposed to be more frequent in formal situations. In 16 children aged between 3;2 and 4;11 from the working class and lower middle class, Roberts $(1994 ; 1997)$ observes a similar result to Chevrot (1991): the girls delete more (-t, d) than the boys. Although the author considers the linguistic data that she collected as being typical of an informal style, we would argue, on the contrary, that they can be considered as formal as those analyzed by Chevrot (1991). The data collection method used by Roberts $(1994 ; 1997)$ consisted of an interview with the researcher during which, amongst other things, the child had to recount family and extra-curricular activities, play store and doctor, tell a story from a picture-book, etc. This type of interview seems to us to be of a formal nature for a number of reasons. Firstly, the author is unfamiliar to the child as the interview is their sole meeting. Secondly, role-playing exercises, in this case playing store or doctor, are known to favor the use of certain types of variants appropriate to the role taken on (Ervin-Tripp 1973; Slosberg-Andersen 1990). Finally, when telling a story to an unfamiliar individual, it can be expected that the child will produce the variants heard in situations when adults adopt a more formal posture, such as during shared reading. We would therefore 
qualify somewhat the observations made by Roberts $(1994$; 1997) by underlining that the situation in which this unexpected gender effect (more non standard variants produced by girls) is apparent is in fact a more formal situation, similar to that in the study carried out by Chevrot (1991).

In point of fact, due to the heterogeneous results, the available data do not allow us to conclude in favor either of the early transmission of usage by parents or of a learning process that occurs throughout childhood and adolescence. Following Chevrot et al. (2000) and Roberts (1994, 1997), we will, however, retain the notion that the emergence of a gender effect could be dependent upon the variable studied. More generally, variants with strong social value in the adult community may be those passed on to girls at an early stage; the other variants, less salient, would thus be acquired later in development through the influence of the peer group, different educational practices according to age or the effect of accumulated input. It would then be necessary to take into account the sociolinguistic status, in the community, of the variables studied in order to interpret results concerning gender (Foulkes et al. 2005) or other factors of variation (Smith et al. 2007; Smith et al. this issue).

2.3.3. Context. The model of acquisition of Standard English put forward by Labov in 1964 suggests that awareness of the social value of variants precedes the ability to vary use according to the communicative context. Thus, according to this author, stylistic adaptation appears at the end of adolescence. In light of the studies presented in this section, we will question the age of such adaptation and the reasons behind it: is it dependent upon an awareness of the social value of uses or does it result from a more automatic association made between certain variants and certain types of interaction?

As early as 1973, Ervin-Tripp summarized the usage of African American Vernacular English (AAVE) during preadolescence (between ages 9 and 13). She indicates that the communicative situation influences the selection of standard variants in children's speech. For example, the usage frequency of standard variants increases when children are role-playing doctor or teacher, are interviewed by an authority figure or are interviewed alone rather than in a group, as well as when the interviewer uses only standard English rather than variable speech (Houston 1969; Kernan 1969; Labov et al. 1968; Williams and Naremore 1969).

Other dialectal varieties of English have been the subject of surveys examining the influence of the communicative situation. On the basis of four situations of decreasing levels 
of formality - reading, formal interview with the researcher, less formal interview with two friends and the researcher, role-playing activity with peers without the presence of the researcher - Reid (1978) observes that 16 Scottish children age 11 vary their use of variants according to the context of the exchange. This result is borne out in the study by Macaulay (1977) comparing a reading-aloud exercise with speech produced during an interview with the researcher, which noted that at age 10 and 15 children produce more standard variants of (l) and (gs) in a reading context. Where the word-final post-consonantal /R/ in French is concerned, Chevrot et al. (2000) notice that, in the more formal exercise (oral gap-filling exercise based on pictures, resembling a school activity), the 10-12 year-olds produce more $/ \mathrm{R} /$ than in the less formal situation (conversation with the researcher comparing pictures). Romaine (1984), for her part, compares the production of the variables (gs), (lng) and (l) in a reading situation and an interview situation. She observes that, from the age of 10, the children are capable of selecting more standard variants in the appropriate situation. From this result, she draws the hypothesis that children of 10 are aware that the use of non standard variants is not appropriate for reading. On this subject, she is in line with the conclusions made by Labov (1964), although she places this awareness of the social value associated with variants at an earlier age. In the 1990s, several variationist studies conducted in different languages observed an earlier stylistic adaptation than that highlighted in the past. For the variable (-1ng) in American English, Patterson (1992) notes that the 48 children of her sample divided into three age groups - 4, 6 and 8 years - use the non standard variant more often in a conversational situation than when recounting a story or in a picture-naming task. She also observes that the interlocutor and the topic of speech influence the selection of variants. As for Roberts (1994), she notes that between $3 ; 2$ and 4;11, children vary their use of the variable (-ıng) according to their interlocutor. Indeed, children select the standard variant more frequently when addressing an adult than when addressing another child. A similar early effect is also evidenced by a study carried out in Scotland on the variable hoose in English. Examining mother-child interactions, Smith et al. (2007) observe that, from the age of 3;2, the 11 young speakers of the study use more non standard variants during daily activities and games than during interactions of an educational (What color is it?) or disciplinary (Behave! Get up!) nature. With respect to a Spanish variable, the intervocalic /d/, Díaz-Campos (2005) notes that when children age 4;6 and 5;11 are emotionally engaged in their speech — situation 
that, following Labov (1972b), the author defines as being informal — they produce more non standard variants than when they answer the researcher's questions, i.e. in a formal situation. Analyzing the productions of a group of kindergarten children, Martin (2005) observes that it is during activities requiring a particular linguistic posture that variable liaisons are most often realized. Indeed, they are used in role-playing situations (playing mom and dad, playing school) pretending to read, staging plays with animals, etc. The author suggests that children acquire certain social knowledge about language through activities that lead them towards a more normative use of variables. One result runs counter to these findings. In children between 3;2 and 4;11, Roberts $(1994,1997)$ notices no adaptation when the variable (-t, d) in English is addressed to an adult, another child or a puppet.

It would therefore appear that children's stylistic adaptation of sociolinguistic variables can occur far earlier than envisaged by Labov (1964) in his model of acquisition. Indeed, the results that we have outlined show that from as early as 3 years old children are capable of selecting variants according to the type of interaction in question (Roberts 1994; Smith et al. 2007). This result is similar to observations regarding acquisition in bilingual contexts. Different studies have shown that from 2-3 years of age children are able to select and use the language of their interlocutor (De Houwer 1990; Ghimenton et al. this issue; Lanza 1992; 2004; Youssef 1991). On this subject, Youssef (1991: 96) claims that “[...] the acquisition of stylistic awareness and the specification of appropriate linguistic behavior to accommodate it is associated with the acquisition of forms per se." These results call into question Labov's initial model according to which situational adaptation emerges with awareness of the social value of variants (Labov 1964). On the contrary, it would seem - as Patterson (1992) underlines - that children acquire patterns of stylistic variation as soon as they participate in daily family interactions. Thus, from their first words, they associate sociolinguistic variants with different types of interaction and it is only later in development that they use these variants as markers of social identity. The author summarizes her position as follows: “[...] stylistic differences precede rather than follow the evaluation of specific variants and the ability to discuss the relationships among variants, social groups, and styles." (Patterson 1992: 178).

2.3.4. Evaluation of sociolinguistic variables and link with production. In this section, given over to the evaluation of sociolinguistic variables, we will call into question one of the 
main assumptions of the labovian model according to which awareness of the social value of variants is not apparent until early adolescence (cf. stage 3 of the acquisition model for Standard English) when the child comes into contact with different linguistic varieties more often (Labov 1964). Furthermore, in light of the works of Chevrot et al. (2000) and Barbu et al. (this issue), we will examine the possible link between production and evaluation.

On the basis of analysis of extracts from interviews including the five phonetic variables (l), (u), (a), (au) and (gs), Macaulay (1977) asked 15 year-old informants to determine the social background and occupation of each of the inhabitants recorded. He observes that the young girls' evaluations are similar to those of adults, which is not the case in the boys of this age. It would therefore seem — and this is the author's hypothesis — that boys are less aware of adult social values than girls. Lafontaine (1986) conducted a large survey with 123 pupils, divided into four age groups $(8,12,14$ and 18 years old) from different social backgrounds in school in the region of Liège (Belgium). Her aim was to examine the attitudes of young Belgian speakers regarding regiolectal and sociolectal features. Variables from different linguistic levels (accent, lexicon, syntax, phonetics, variable liaisons) were put forward for evaluation by the children. Using individual interviews involving different types of tasks open questions, closed questions, judgments of acceptability on pairs of variants, autoevaluation, etc. - she comes to the conclusion that children, even at a very young age, are aware that linguistic material is subject to certain rules and norms. This early normative judgment is apparent from as early as 8 years of age. However, even if children produce speech in which markers of normative judgment appear, such as "well-spoken"/"badlyspoken", Lafontaine (1986) underlines that these markers are not based on the same criteria as for adults. For children, they refer to the truth-value or the politeness of the utterance they are evaluating. It would seem that it is only from the age of 9-10 years that the first justifications for linguistic norms based on context/interlocutor are verbalized (Buson 2009; Buson and Billiez this issue). This is also the age at which children's judgments of regional accents are negative and they favor standard variants. This is also the case where the different sociolectal variables evaluated are concerned: from age 12 the children identify the standard variants as being more 'prestigious' or more 'appropriate'. According to Lafontaine (1986), the prescriptive and normative discourse of the school institution instils in pupils a system of common rules that place value on standard variants and bring children's judgments in line with those of adults. In the context of Australian English, Martino (1982) also examines the judgments of ten boys age 10, divided into two social backgrounds - working class and 
lower middle-class - regarding the consonantal variable $/ \theta /$. She concludes that children from both backgrounds are aware of the prestigious social value ascribed to realizing $[\theta]$. Despite this awareness, working-class children claim to prefer the non standard variant $[\mathrm{f}]$ that they are more familiar with and that, with one exception, they use systematically. This result can be compared with the study carried out by Trudgill (1975) in Norwich (England), in which the author observes that adult males of the working class prefer to use the non standard variant of (ng), despite recognising the prestige value of the standard variable. Analyzing an auto-evaluation test, Trudgill (1975) concludes that this preference for non-prestige variants is due to covert norms, hidden values to which speakers do not admit within the interview context, displaying loyalty towards the social group of origin.

The studies outlined above situate the beginnings of evaluation in line with that of adults at age 10-12 at the earliest. Only one study places this at an earlier age. Chevrot et al. (2000) conducted a study of the evaluation of the word-final post-consonantal /R/ in French with a group of 24 children age 6-7 and another group of 24 children age 10-12. The children were led to judge the acceptability of different utterances using the variable in question and asked to state whether the speaker spoke "well" or "badly". The authors note that children age 6-7 make an unfavorable judgment of the lack of the phoneme /R/ before a pause. When $/ \mathrm{R} /$ is followed by a consonant-initial or vowel-initial word, the 6-7 year-olds do not make different judgments. In other words, no attested difference exists between the judgments in favor of the conservation of $/ \mathrm{R} /$ and those in favor of deletion of the variable. At age 10-12, the children's preference for conserving $/ \mathrm{R} /$ before a pause extends to the pre-vocalic context. In both age groups, the authors observe the relative homogeneity of the judgments because no influence of social background can be noted. This result is in keeping with the results obtained by Labov (1972b, 1976) in adults; despite social stratification of use, speakers share common evaluative norms.

Finally, the comparison of production and evaluation gives disparate results. Whereas the absence of $/ \mathrm{R} /$ before a consonant is not detected by the children age 6-7 or 10-12 in the evaluation task, Chevrot et al. (2000) note a very clear situational adaptation regarding this context: in children of 10-12, whatever their gender or social background, pre-consonantal /R/ 
is realized more often in formal than in informal situations. The opposite result is observed for $/ \mathrm{R} /$ before a vowel or a pause. Even if the deletion of the phoneme is judged unfavorably in the evaluation task, the situational adaptation is far less clear: only the 10-12 year-old girls from a higher-class environment alter their productions depending on the context. According to the results of Chevrot et al. (2000), it would seem that the ability to adapt speech to the situation is not dependent upon the ability to formulate judgments placing value on the variants used in formal situations. A study by Barbu et al. (this issue), conducted on the production and evaluation of variable liaisons with 185 children between age 2 and 6 divided into four age groups $(2-3,3-4,4-5,5-6)$, seems to run counter to this observation. Firstly, the authors note no noteworthy evolution of judgments in favor of standard variants between ages 2 and 6. Secondly, they find a significant effect of social background (upper versus lower class) on the standard judgments that becomes most apparent at 5-6 years old; upper-class children form more standard judgments than lower-class children. Finally, they observe that a significant correlation between the production and evaluation of variable liaisons is apparent at age 4-5 and age 5-6 whatever the social background. Thus, the children between 4 and 6 years old who make the most positive evaluations of standard variants are also those who produce them the most often in a formal situation (the production exercise consisted in naming pictures). Bringing together the studies by Chevrot et al. (2000) and Barbu et al. (this issue), it could be thought that at early stages the acquisition of patterns of usage of sociolinguistic variables is not guided by awareness of the social value of usage. In the youngest children, familiarity with certain variants - more or less standard depending on their background - would thus guide both production and evaluation. The differences according to social background noted in very young children's evaluation could be transitory and linked to the children's linguistic environment. One hypothesis is therefore that schooling instils in individuals the norms of standard language leading to recognition of this variety by all speakers of the community ${ }^{4}$. Indeed, from the age of 6-7 (when children begin elementary school) Chevrot et al. (2000) note social uniformity of evaluations. A more precise way of testing this hypothesis would be to compare the acquisition of sociolinguistic uses in communities where children go to school at different ages, by linking the use and evaluation of sociolinguistic variables in teachers, caregivers and pupils.

2.3.5. Age. The impact of schooling on children's sociolinguistic patterns may also be revealed in examining the way the overall mass of variants produced evolves with age. Where 
standard variants are concerned, no study has observed an increase in their level of production below the age of 6 . Roberts (1994), who compared the productions of children age 3 with those of children age 4 , notes no age effect in the production of the variable (-t, d) or the variable (lng). Other studies indicate an increase in non standard variants - and so a decrease in standard variants — as development progresses. For example, Smith et al. (2007) observe that the three youngest subjects of their sample (aged 2;10, 2;11 and 3;0) were almost categorical in their use of the standard variant of the variable hoose whereas the older children (aged between 3;2 and 3;6) used the non standard variant more frequently. Chabanal (2004) presents the same type of result, noting that Pierre, a young subject of his longitudinal study, deleted more liquid $/ 1 /$ and $/ R /$ in his fourth year than in his third year. This increase in non standard variants observed at early ages could be due to the input received by the children. Indeed, work by Foulkes et al. (2005) and Smith et al. (2007) has highlighted that the frequency of standard variants in speech addressed to children by their mother reduces as they grow older. It would also seem that peer input could direct children's linguistic uses towards less standard forms. In a longitudinal study of a group of 11 children in kindergarten (mean age in period 1: 4;7, in period 2: 5;7), Nardy (2008) observed the children's social network and their use of three sociolinguistic variables in French (variable liaison, post-consonantal word-final /R/, /1/ in the clitic pronouns il(s) ('he/they') and elle(s) ('she/they')). Using an ethological method of direct observation of social behaviour within the group instantaneous scan sampling (Altmann 1974; Santos et al. 2000) — she quantified the frequency of verbal interactions between each member of the group. Furthermore, she collected the children's productions in two very distinct situations: one formal situation during which the children told a story to an unknown adult and one informal situation consisting in spontaneous verbal exchanges among peers. The analyses carried out show that from period $1(4 ; 7)$ to period $2(5 ; 7)$, the level of standard variants produced by the children decrease in both situations. However, this decrease only reaches the level of statistical significance in the formal situation. Furthermore, there is a link between the quantity of verbal interactions between individuals and their use of variables. Thus, the more two individuals interact, the more similar their use of sociolinguistic variables. Moreover, the children who interact the most are those who use the most non standard variants. They could therefore direct the whole group towards less standard use of variants. 
From the age of 6, and until 10-12 years of age, Romaine (1984), Patterson (1992) and Chevrot et al. (2000) note an increase in the production of standard variants in formal situations. Again, we can suppose that entering the education system (at roughly 6 years old depending on the country) as well as discovering and learning the written form, may be factors favoring the increase of standard variants in children's speech in formal situations.

Despite these general tendencies, the question of the way in which the overall mass of variants produced by children evolves with age, as posed by different authors, remains partial. As underlined by Chevrot et al. (2000: 297), "the major question is to identify not how the overall mass of nonstandard variants develops, but rather how their usage changes in each situation and for each category of speakers." In short, it would seem that the question of evolution with age deserves to be examined in two stages: firstly over the pre-school period (increase in non standard variants in family interactions) and secondly, over the school period (increase in standard variants in formal situations).

2.3.6. Future issues to explore and necessary data. The review of available research lays down a number of milestones specifying how sociolinguistic regularities are established in the course of development. Firstly, childhood differences according to the social status of parents are established fairly early — from the age of 3-4 years — and could increase until the age of 6. Secondly, stylistic ability to adapt the use of variants to social context also appears from as early as 3 years old within family interactions. Thirdly, regarding the gender effect, the results are contradictory (depending on the study, there are no differences according to gender, more standard variants in girls or more standard variants in boys). Fourthly, the changes in use of variants with age do not seem to be linear. The results remain partial, but they suggest an increase in non standard variants until the age of 6 , followed by an increase in standard variants in formal situations during the school years. Finally, research by Chevrot et al. (2000) and Barbu et al. (this issue) suggests that early developmental changes in the use of variants are not linked to changes in their evaluation, but rather to the frequency of variants in the child's environment. It is necessary to establish these developmental milestones, however they often remain descriptive and do not explain the principles guiding the acquisition process. In order to explain these principles, certain theoretical questions must be explored further and new types of data must be collected.

The first issue concerns the influence of the linguistic environment on the acquisition of sociolinguistic variables. We reported evidence showing the effect of parental input but also 
that the caregivers themselves adjust the frequency of the variants according to the age of the children (Foulkes et al. 2005; Smith et al. 2007). Considering that the child and the caregiver form a dynamic system of mutual adjustments that boosts development, one kind of necessary data would be long-term longitudinal studies on caregiver-child dyads. Another expected benefit of such a longitudinal study linking input and acquisition would be to confirm the hypothesis that the cumulative effect of input is at the origin of the increase in social differences between the ages of 3 and 6 (Chevrot et al. 2011; Nardy 2008).

The second issue concerns the motor for development. Is children's progress driven by learning the sociolinguistics norms and values of their community? Or is it the result of the implicit learning of statistical regularities encountered in input? Although certain studies highlight that early developmental changes in the use of variants are not linked to changes in their evaluation, but rather to the frequency of variants in the child's environment (Barbu et al. this issue; Chevrot et al. 2000), one cannot exclude the possibility that later modifications in production are the result of the children or parents' awareness of norms.

From this perspective, it is important to take into account the sociolinguistic salience of variants in the community. The most salient sociolinguistic variants within a given community could be more strongly linked to identities and social roles. Therefore, their social meaning would be more directly accessible to children and more likely to orient their production. Furthermore, in child-directed speech, it is likely that caregivers control their use of these salient variables to differing degrees depending on the social role attributed to the child, and particularly the child's gender (Foulkes et al. 2005; Smith et al. 2007; Smith et al. this issue).

More generally, the respective influence of statistical learning and social norms and identities during acquisition remain to be specified since both factors are not mutually exclusive. In the context of naturalistic observations, this aim requires data to be collected that links production and evaluation, in children, in child-directed speech and in the community in general. In a more experimental framework, in the wake of studies carried out in adults in the field of sociolinguistic cognition (Campbell-Kibler 2010; Labov et al. 2011; Loudermilk et al. 2011), experiments based on priming methods (Hay and Drager 2010; Squires 2011; Staum Casasanto 2009) could enable us to determine the degree of automatic and implicit knowledge at play in the relationships between linguistic and social knowledge, at different ages. Thus, future observations will need to determine the role of explicit and implicit knowledge in the 
acquisition of sociolinguistic variation and how these two types of knowledge interact, contradict each other or converge.

\section{Models for the acquisition of variation}

Numerous tendencies and perspectives raised by this review of questions have shown that patterns of variation are acquired at an early stage and have also highlighted the key role played by the frequency of forms encountered in the input during the acquisition process. A theory of the acquisition of variation must therefore fulfil a number of criteria. It must account for the effect of the frequency of variants. It must also explain the construction of the relationship between linguistic and social information. Finally, as with all developmental theories of language, it must explain the process of generalization. After a brief presentation of the three main learning mechanisms for variation suggested in sociolinguistic literature abstract variable rule formation, case-by-case concrete learning and exemplar theory - we will discuss these models in light of the criteria cited above.

\subsection{Abstract variable rule formation}

It is to Labov (1972a) that we owe the concept of variable rules. Extending the concept of optional rules, stemming from generative grammar, to that of variable rules, he includes within the very structural description of the rule the frequency of its operation and the weight of constraints upon its level of application (internal constraints and social characteristics of the speakers). In the first stages of formulating the notion of variable rules, Labov did not specify whether it was a mechanism describing the structure of language or modelling cognitive function. However, when addressing the question of the acquisition of variation, he clarified his position somewhat. According to Labov (1989) and other authors who followed

this theoretical framework (Patterson 1992; Roberts 1994; 1997; Smith et al. 2007), at an early age the child constructs variable rules manipulating abstract categories (noun, verb) from the initial forms encountered in his environment. Very early on, the general format of these abstract rules would correspond to those of adult speakers with the exception of some characteristics specific to children. Being exposed to input would then encourage the adjustment of variable constraints in accordance with those used by adult speakers 
surrounding the child. Running counter to this theory, other researchers put forward the notion of case-by-case concrete learning which does not assume the same degree of generalization and the early mastery of abstract categories.

\subsection{Case-by-case concrete learning}

Several authors who have also questioned the acquisition of the mechanisms underpinning the functioning of variable linguistic units note that the variation observed in children's productions is subject to strong lexical conditioning. According to these authors, this result does not seem very compatible with the generalization process entailed by a rule, which, by definition, is applied indifferently to all lexical items (Chevrot et al. 2000; Díaz-Campos 2004; Wolfram 1989). From an early age, the production of variable forms would thus be linked to the frequency of each carrier word in input. The more frequent a lexical item, the more opportunities children have to learn and reproduce the patterns of variation with which it is associated (absence or presence of variation, weighting of variants). In this view, therefore, at no point do children generalize rules based on abstract categories. The variation in child productions can be seen as the result of 'weighted' memorization of concrete variants. In the following section, we will outline a third mode of learning sociolinguistic variables, elaborated in the context of exemplar theory. It links the copying of surface forms with the ability to infer more abstract categories.

\subsection{Exemplar theory}

Exemplar theory posits that linguistic knowledge is constructed through memorization of the traces of an individual's language experiences (Bybee 2006). Within this conceptual view, memorizing a linguistic form or an utterance amounts to memorizing not only the target information but also a set of social and contextual elements such as the type of speaker, the acoustic characteristics of his voice (Foulkes and Docherty 2006; Pierrehumbert 2001), information about the communicative situation (casual versus formal) (Bybee 2003), etc.. Thus, as suggested by Foulkes et al. (2001: 80) "the details encoded at the holistic stage of representation will include features which have sociolinguistic relevance among the adult 
community". In this view, each linguistic unit would be represented in memory by a series of exemplars corresponding to all the realizations of this unit (Pierrehumbert 2001, 2002, 2003). Frequent linguistic units would thus be represented by more exemplars than less frequent linguistic units (Bybee 2002) even if the experience with the input is also mediated by factors such as attention and saliency (Foulkes 2010; Pierrehumbert 2006). Concerning the degree of availability of an exemplar, it would depend upon its strength in memory and how recently it has been activated in reception and production (Pierrehumbert 2001, 2002) as well as upon neighbouring exemplars in the phonological space (Pierrehumbert 2003).

Foulkes et al. (2001) put forward a model for the acquisition of phonological variation within the framework of exemplar theory. The authors defend the notion of a bottom-up learning process in which the environment plays a leading role in acquisition. According to this view, in an initial phase, upon contact with input children memorize different exemplars for the same word. Each exemplar memorized includes certain information about the speaker, his pronunciation, the situation, etc. After an initial lexical store has been established, children proceed to a more abstract analysis on the basis of similarity between different exemplars. This process would thus lead them in principle to replicate the use of the variable in the linguistic environment to which they are exposed. In this context, the encoding of variation and its factors starts at a very early stage, as soon as the child comes into contact with his linguistic environment and begins to memorize elements of it.

\subsection{Comparing the models}

We shall now compare the different learning mechanisms for the acquisition of variation variable rules, case-by-case learning and exemplar theory - retaining the three criteria derived from our review of the literature: the necessity to account for the role of the environment and the effect of frequency, the relationship between linguistic and social information, and processes of abstraction and generalization.

The role of the environment is fundamental in each learning mechanism, along with the degree of frequency of perceived forms which influences acquisition. Despite this common characteristic, the different theories can be set apart on the other levels. Where the relationship between linguistic and social information is concerned, exemplar theory advances that these two types of information are in principle memorized and encoded simultaneously from the beginning of the learning process. In the context of learning variable rules, social 
information is seen to be contained in the weighting of external constraints that determine the degree of applicability of the rule. In this perspective, the relationship between linguistic and social information is only established once the general format of the rule is in place whereas, in the case of learning by exemplars, social information is inherent to the memorization of variants. Finally, where case-by-case learning is concerned, the authors do not address the question of the relationship between social and linguistic information.

The models also differ regarding the process of abstraction. It is not envisaged within the framework of case-by-case learning. The authors claim that the child retrieves and memorizes surface forms before then producing them, without mentioning relationships between these forms. The authors defending the notion of learning variable rules consider that the child generalizes rules that operate on abstract categories, which are available from an early age. They do not, however, provide a more detailed description of the process that leads to the creation of these categories and rules on the basis of the linguistic environment.

All things considered, exemplar theory seems to be the most promising framework to account for the tendencies observed in sociolinguistic studies concerning children. Contrary to variable rules and case-by-case learning, this theory takes into account the early link between linguistic and social information, explains how this link is constructed, and also highlights the impact of frequency of perceived forms within the linguistic environment. However, as conceded by Foulkes (2006: 25-26), the exemplar approach does not explain "to what extent the store of traces is subject to abstraction, what form that abstraction takes, or what role (if any) the abstract representation plays in speech production or perception." It is for this reason that we shall now turn to usage-based theory, which seems to offer the most comprehensive framework including the tenets of exemplar theory and accounting for the process of generalization.

\section{Perspectives: usage-based theory as a model for variation acquisition}

Usage-based theories suggest that usage is the key to understanding the way linguistic systems are formed, and how they function and evolve. More specifically, linguistic knowledge is structured through usage events, i.e. concrete utterances that the speaker produces and hears (Kemmer and Barlow 2000). The frequency of linguistic experiences therefore has a central role to play. Upon contact with usage events, children are thought to 
memorize concrete pieces of language formed from a sound sequence that is associated with other information retrieved from the interactional context. Depending on the specific case, these concrete pieces of language may correspond to a single adult word or to a sequence of words memorized as a frozen phrase (Tomasello 2003). By connecting the memorized sequences on the basis of their formal or functional similarities, children generalize schemas allowing them to produce utterances that they have never heard before (Tomasello 2003). In this way, on the basis of stable and recurrent items, they establish a first level of abstraction. For example, by connecting stored sequences sharing the lexical item it's, such as it's daddy, $\underline{i t ' s} m e, \underline{i t}$ 's the dog, they would eventually generalize an item-based schema of the type it's + $X$, where $\mathrm{X}$ is a slot into which new elements can be inserted. During the course of development, these patterns are reorganized into networks forming more complex and abstract schemas, which are not necessarily founded upon a shared lexical item. According to Tomasello (2003, 2006), this process of abstraction takes place through two simultaneous cognitive processes. Firstly, the process of analogy, which erases the concrete elements of the schemas that become abstract elements defined according to their role in the relational structure. Secondly, functionally-based distributional analysis allows the emergence of categories such as "noun", "verb", etc. formed from specific terms that fulfil a similar communicative role in the perceived and produced utterances. It should also be noted that a schema is a mechanism that encodes patterns of connection between memorized traces of language experiences. In contrast to rules, schemas do not exist independently of the stored sequences from which they emerge (Kemmer and Barlow 2000). Moreover, schemas explain the way the child moves from stored concrete usage-events to more abstract categories.

This general framework of language acquisition, elaborated by Tomasello (2003), does not address the issue of sociolinguistic variation per se. Nonetheless, we believe that it constitutes a promising framework as it fulfils all three criteria necessary for a theory of the acquisition of variation. As with exemplar theory, linguistic knowledge depends upon the nature and frequency of usage events encountered in the environment, and social information is constitutive of the traces memorized from these usage events. Furthermore, the emergence of more abstract categories is a gradual process based on links made between a stock of memorized traces leading to the formation of schemas or constructions (Goldberg 2003).

Nardy (2008) applied this conceptual framework to the acquisition of a French sociolinguistic marker well-documented and formalized in adults: the variable liaison (inter alia, Armstrong 2001; Bybee 2001; Durand and Lyche 2008; Encrevé 1988). All the studies 
that have focused upon social background concur in showing that the realization of variable liaisons is more frequent in higher-class adults (Ashby 1981; Booij and De Jong 1987; De Jong 1994). The model put forward by the author concerns more specifically the variable liaison between an adjective and a noun: for example in the sequence gros arbre 'big tree', the liaison consonant /z/ can be realized ([gвоzавbь]) or not realized ([gвоавbь]). This model integrates the numerous psycholinguistic observations that show that the liaison consonant is encoded early on with the initial of the variants of the nouns that follow. In this way, a noun such as arbre 'tree', encountered after the liaison consonants /n/, /z/ and /t/ would take three forms in children's lexicon: /павьь/, /zавьь/ and /тавьь/. Furthermore, these consonant-initial variants would coexist with a vowel-initial variant (/авьь/), drawn from contexts where the noun is not preceded by a liaison consonant (joli arbre 'pretty tree') (Chevrot et al. 2007; Chevrot et al. 2009; Dugua et al. 2009; Gallot et al. 2009). Nardy (2008) hypothesises that at an early age children memorize frequent or salient adjective-noun sequences in input, some of which can be associated with individuals or particular interactions. The impact of social environment upon the acquisition process could thus been seen as being established from this early stage. Due to the variable nature of liaisons, children from all backgrounds hear and memorize adjective-noun sequences with and without liaisons. They would therefore generalize two competing schemas. Firstly, linking the sequences including a liaison, they would generalize a schema of the type gros $+/ \mathrm{zX} /$, which specifies that the adjective gros should be followed by the variant of the noun beginning with / $\mathrm{z} /$ ([gвоzаньь $]$ ). Such schemas thus allow the realization of the liaison. Secondly, connecting sequences without a consonantal liaison, they would elaborate a schema of the type gros + /[vowel $] \mathrm{X} /$ that selects the variant of the vowel-initial noun after the adjective ([двоавьь]). This second type of schema allows non-realization of liaisons. As higher-class children hear more variable liaisons realized in their family environment, they would therefore generalize the schema gros $+/ \mathrm{zX} /$ more rapidly than their lower-class counterparts. This head start would account for patterns of results concerning the progressive increase in social differences for the acquisition of variable liaisons between the ages of 2 and 6 (see Section 2.3.1). Indeed, initial social differences could be the result of the nature of sequences memorized (with or 
without liaison). This difference would then become more marked when higher-class children generalize the schemas carrying liaisons before lower-class children.

This general framework for acquisition seems to us to be of very real interest when it comes to accounting for the acquisition of variation as it gives concrete existence to the process of abstraction, unlike other theoretical frameworks. The notion of competing schemas accounts for the cognitive selection of variants (Bybee 2001), as well as for the selection of morphosyntactic structures and lexical units more generally. Moreover, within this theory the generalizations established are not disconnected from concrete events perceived and memorized by the speaker. This assumption entails two main consequences. First, schemas are associated with social information contained in the memorized exemplars upon which they are based. Second, schemas are not fixed but dynamic insofar as they can continue to be updated throughout life. Applying this integrative framework to sociolinguistic variation thus appears a promising direction to take. As Dirk Geeraerts underlined in an interview with Juana Isabel Marín-Arrese (Marín-Arrese 2007: 294): “[...] in the actual practice of a usagebased enquiry, grammatical analysis and variationist analysis will go hand in hand". This alliance implies reinforcing methodological exchanges and theoretical integration between developmental psycholinguistics and sociolinguistics.

\section{Notes}

1. The variable transcribed as (t) by Reid (1978) is the same as that transcribed as (gs) by Macaulay (1977). It is the variation that affects /t/, realized either with an alveolar plosive [t] (butter $[: \beta \wp \tau \leftrightarrow])$ 一 or a glottal plosive — [?] (butter $[: \beta \wp ? \leftrightarrow])-$.

2. The variable transcribed as (ng) by Reid (1978) is the same as that transcribed as (ng) by Fischer (1958), Romaine (1984), Patterson (1992) and Roberts (1994). This variable takes two variants: nasal velar plosive [y] (correcting $[\kappa \leftrightarrow: \rho \varepsilon \kappa \tau \mathrm{IN}]$ ) and nasal alveolar plosive [n] (correcting $[\kappa \leftrightarrow: \rho \varepsilon \kappa \tau \mathrm{IV}])$.

3. Martin established her social indices by ascribing a score between 1 and 3 to the parents' occupation. 1 corresponds to the occupations of group 3 in the INSEE index (teachers, engineers etc.) [INSEE: Institut National de la Statistique et des Études Économiques - French National Institute of Statistic and Economic Studies]. 2 corresponds to groups 4 and 5 (nurses, 
The acquisition of sociolinguistic variation 28

commercial agents, etc.) and 3 corresponds to laborers or drivers (group 6 in the INSEE index) (Desrosières and Thévenot 1988).

4. This conclusion is compatible with the results of Day (1980) concerning children's evaluation of local variants (Hawaii Creole English) and standard variants (Standard English) in 87 kindergarten and first-grade children divided into two groups: those living in an advantaged area and those living in a disadvantaged area. Day noted a social difference in evaluations by the kindergarten children whereas no difference of this type could be seen in the first-graders. However, contrary to the studies cited in our review, Day's research focused on the global evaluation of syntactic, phonological and prosodic variants without distinction.

\section{References}

Altmann, Jeanne. 1974. Observational study of behavior: sampling methods. Behaviour 49(3). 227-267.

Armstrong, Nigel. 2001. Social and stylistic variation in spoken French: a comparative approach. Amsterdam, Philadelphia: John Benjamins.

Ashby, William. 1981. French liaison as a sociolinguistic phenomenon. In William Cressey \& Diana Napoli (eds.), Linguistics Symposium on Romance Languages (9th), 46-57. Washington DC: Georgetown University Press.

Barbu, Stéphanie. 2000. Les relations sociales entre enfants à l'école maternelle: bases comportementales et langagières. Rennes: Université de Rennes 1 Ph.D. dissertation.

Barbu, Stéphanie, Aurélie Nardy, Jean-Pierre Chevrot \& Jacques Juhel. This issue. Language evaluation and use during early childhood: adhesion to social norms or integration of environmental regularities?

Beaulieu, Louise \& Wladyslaw Cichocki. 2002. Le concept de réseau social dans une communauté acadienne rurale. Canadian Journal of Linguistics 47(3-4). 123-150.

Booij, Geert \& Daan De Jong. 1987. The domain of liaison: theories and data. Linguistics 25(5). 1005-1025.

Bornstein, Marc H., O. Maurice Haynes \& Kathleen M. Painter. 1998. Sources of child vocabulary competence: a multivariate model. Journal of Child Language 25(2). 367-393.

Buson, Laurence. 2009. Variation stylistique entre 5 et 11 ans et réseaux de socialisation scolaire: usages, représentations, acquisition et prise en compte éducative. Grenoble: Université Stendhal Ph.D. dissertation.

Buson, Laurence \& Jacqueline Billiez. This issue. Representations of stylistic variation in 911 year-olds: cognitive processes and salience.

Bybee, Joan L. 2001. Frequency effects on French liaison. In Joan L. Bybee \& P. Hopper (eds.), Frequency and the emergence of linguistic structure, 337-359. Philadelphia: John Benjamins. 
Bybee, Joan L. 2002. Phonological evidence for exemplar storage of multiword sequences. Studies in Second Language Acquisition 24(2). 215-222.

Bybee, Joan L. 2003. Phonology and language use. Cambridge: Cambridge University Press. Bybee, Joan L. 2006. From usage to grammar: the mind's response to repetition. Language 82(4). 711-733.

Campbell-Kibler, Kathryn. 2010. New directions in sociolinguistic cognition. University of Pennsylvania Working Papers in Linguistics 15(2). 31-39.

Chabanal, Damien. 2001. L'acquisition de phonèmes variables: influences orthographique et sociolectale. Travaux de Didactique de FLE 45. 87-96.

Chambers, J. K. 1995. Sociolinguistic theory: linguistic variation and its social significance. Oxford: Blackwell.

Cheshire, Jenny. 1982. Variation in an English dialect: a sociolinguistic study. Cambridge: Cambridge University Press.

Chevrot, Jean-Perre, Aurélie Nardy \& Stéphanie Barbu. 2011. Developmental dynamics of SES-related differences in children's production of obligatory and variable phonological alternations. Language Sciences 33(1). 180-191.

Chevrot, Jean-Pierre. 1991. La variation phonétique chez des enfants de 6 à 12 ans: aspects développementaux et incidence des apprentissages alphabétiques. Grenoble: Université Stendhal Ph.D. dissertation.

Chevrot, Jean-Pierre, Laurence Beaud \& Renata Varga. 2000. Developmental data on a French sociolinguistic variable: the word-final post-consonantal /R/. Language Variation and Change 12(3). 295-319.

Chevrot, Jean-Pierre, Damien Chabanal \& Céline Dugua. 2007. Pour un modèle de l'acquisition des liaisons basé sur l'usage: trois études de cas. Journal of French Language Studies 17(1). 103-128.

Chevrot, Jean-Pierre, Céline Dugua \& Michel Fayol. 2009. Liaison acquisition, word segmentation and construction in French: a usage based account. Journal of Child Language 36(3). 557-596.

Coupland, Nikolas. 1980. Style-shifting in a Cardiff work-setting. Language in Society 9(1). $1-12$.

Coupland, Nikolas \& Adam Jaworski. 1997. Sociolinguistics: a reader and coursebook. Basingstoke: Macmillan Press.

Day, Richard R. 1980. The development of linguistic attitudes and preferences. TESOL Quarterly 14(1). 27-37.

De Houwer, Annick. 1990. The acquisition of two languages from birth: a case study. Cambridge: Cambridge University Press.

De Jong, Daan. 1994. La sociophonologie de la liaison orléanaise. In Chantal Lyche (ed.), French generative phonology: retrospective and perspectives, 95-130. Salford: Association for French Language Studies in association with the European Studies Research Institute.

Desrosières, Alain \& Laurent Thévenot. 1988. Les catégories socioprofessionnelles. Paris: La Découverte. 
Díaz-Campos, Manuel. 2004. Acquisition of sociolinguistic variables in Spanish: do children acquire individual lexical forms or variable rules? In Timothy Face (ed.), Laboratory approaches to Spanish phonology, 221-236. Berlin: Mouton de Gruyter.

Díaz-Campos, Manuel. 2005. The emergence of adult-like command of sociolinguistic variables: a study of consonant weakening in Spanish-speaking children. In David Eddington (ed.), Selected proceedings of the 6th conference on the acquisition of Spanish and Portuguese as first and second Languages, 56-65. Somerville: Cascadilla Proceedings Project.

Docherty, Gerard, Paul Foulkes, Jenny Tillotson \& Dominic Watt. 2006. On the scope of phonological learning: issues arising from socially-structured variation. In Louis Goldstein, Douglas H. Whalen \& Catherine T. Best (eds.), Laboratory Phonology 8, 393-421. Berlin: Mouton de Gruyter.

Dugua, Céline, Elsa Spinelli, Jean-Pierre Chevrot \& Michel Fayol. 2009. Usage-based account of the acquisition of liaison: evidence from sensitivity to plural/singular orientation of nouns. Journal of Experimental Child Psychology 102(3). 342-350.

Durand, Jacques \& Chantal Lyche. 2008. French liaison in the light of corpus data. Journal of French Language Studies 18(1). 33-66.

Encrevé, Pierre. 1988. La liaison avec et sans enchaînement. Paris: Édition du Seuil.

Ervin-Tripp, S. 1973. Language acquisition and communicative choice. Stanford: Stanford University Press.

Fischer, John L. 1958. Social influences on the choice of a linguistic variant. Word 14(1). 4756.

Foulkes, Paul. 2006. Phonological variation: a global perspective. In Bas Aarts \& April Mcmahon (eds.), The handbook of English linguistics, 625-669. Malden: Blackwell.

Foulkes, Paul. 2010. Exploring social-indexical variation: a long past but a short history. Laboratory Phonology 1. 5-39.

Foulkes, Paul \& Gerard Docherty. 2006. The social life of phonetics and phonology. Journal of Phonetics 34(4). 409-438.

Foulkes, Paul, Gerard Docherty \& Dominic Watt. 2001. The emergence of structured variation. University of Pennsylvania Working Papers in Linguistics 73. 67-84.

Foulkes, Paul, Gerard Docherty \& Dominic Watt. 2005. Phonological variation in childdirected speech. Language 81(1). 177-206.

Gallot, Sophie, Elsa Spinelli, Jean-Pierre Chevrot \& Céline Dugua. 2009. Le rattachement lexical de la liaison: une expérience d'amorçage chez des enfants pré-lecteurs. Psychologie Française 54. 355-361.

Ghimenton, Anna, Jacqueline Billiez \& Jean-Pierre Chevrot. This issue. Language choice and acquisition in the multilingual society of Veneto (Italy): statistically-driven and pragmatically motivated adjustments between a young child and his entourage.

Giles, Howard \& Peter Powesland. 1975. Speech style and social evaluation. London: Academic Press.

Goldberg, Adele E. 2003. Constructions: a new theoretical approach to language. Trends in Cognitive Sciences 7(5). 219-224. 
Gumperz, John J. 1989. Sociolinguistique interactionnelle: une approche interprétative. Paris: Université de la Réunion \& l'Harmattan.

Hay, Jennifer \& Katie Drager. 2010. Stuffed toys and speech perception. Linguistics 48(4). 865-892.

Hoff, Erika. 2002. Causes and consequences of SES-related differences in parent-to-child speech. In Marc H. Bornstein \& Robert H. Bradley (eds.), Socioeconomic status, parenting and child development, 147-160. Mahwah: Lawrence Erlbaum Associates.

Hoff, Erika. 2003. The specificity of environmental influence: socioeconomic status affects early vocabulary development via maternal speech. Child Development 74(5). 1368-1378.

Hoff, Erika, Brett Laursen \& Twila Tardif. 2002. Socioeconomic status and parenting. In Marc H. Bornstein (ed.), Handbook of parenting, 231-252. Mahwah: Lawrence Erlbaum Associates.

Houston, Susan. 1969. A sociolinguistic consideration of the Black English of children in Northern Florida. Language 45. 599-607.

Ingram, John, Jeffery Pittam \& D. Newman. 1985. Developmental and sociolinguistic variation in the speech of Brisbane schoolchildren. Australian Journal of Linguistics 5(2). 233-246.

Johnson, Joanne. 2003. Phonetic differences in child-directed speech to opposite sex twins. Newcastle: University of Newcastle BSc dissertation.

Kemmer, Suzanne \& Michaël Barlow. 2000. Introduction: a usage-based conception of language. In Michaël Barlow \& Suzanne Kemmer (eds.), Usage-based models of language, vii-xxviii. Stanford: CSLI Publications.

Kernan, Claudia M. 1969. Language behavior in a Black urban community. Monographs of the Language-Behavior Research Laboratory, $\mathrm{n}^{\circ} 2$. Berkeley: University of California.

Kerswill, Paul. 1996. Children, adolescents, and language change. Language Variation and Change 8 (2). 177-202.

Labov, William. 1964. Stages in the acquisition of Standard English. In Roger Shuy, Alva Davis \& Robert Hogan (eds.), Social Dialects and Language Learning, 77-104. Champaign: National Council of Teachers of English.

Labov, William. 1972a. Language in the inner city: studies in the Black English Vernacular. Oxford: Basil Blackwell.

Labov, William. 1972b. Sociolinguistic patterns. Oxford: Blackwell.

Labov, William. 1976. Sociolinguistique. Paris: Éditions de Minuit.

Labov, William. 1989. The child as linguistic historian. Language Variation and Change 1(1). 85-97.

Labov, William. 1990. The intersection of sex and social class in the course of linguistic change. Language Variation and Change 2(2). 205-254.

Labov, William. 1994. Principles of linguistic change, vol. 1: internal factors. Oxford, Cambridge: Blackwell.

Labov, William. 2001. Principles of linguistic change, vol. 2: social factors. Oxford: Blackwell. 
Labov, William, Sharon Ash, Maya Ravindranath, Tracey Weldon, Maciej Baranowski \& Naomi Nagy. 2011. Properties of the sociolinguistic monitor. Journal of Sociolinguistics 15(4). 431-463.

Labov, William, Paul Cohen, Clarence Robins \& John Lewis. 1968. A study of the nonstandard English of Negro and Puerto Rican speakers in New-York City. Final report, OE-610-059. New York: Columbia University.

Lafontaine, Dominique. 1986. Le parti pris des mots. Bruxelles: Mardaga.

Lanza, Elizabeth. 1992. Can bilingual two-year-olds code switch? Journal of Child Language 19(3). 633-658.

Lanza, Elizabeth. 2004. Language mixing in infant bilingualism: a sociolinguistic perspective. New York: Oxford University Press.

Loudermilk, Brandon, Eva Gutierrez \& David Corina. 2011. What are you talkin' about? Processing sociolinguistic variation: an ERP study. Paper presented at the 24th Annual CUNY Conference on Human Sentence Processing, Stanford University, 24-26 March.

Macaulay, Ronald K.S. 1977. Language, social class, and education: a Glasgow study. Edinburgh: Edinburgh University Press.

Marín-Arrese, Juana I. 2007. Dirk Geeraerts: cognitive sociolinguistics and the sociology of cognitive linguistics. Annual Review of Cognitive Linguistics 5. 289-305.

Martin, Nathaël. 2005. Réseaux sociaux et variations phonétiques. Grenoble: Université Stendhal Master 1 dissertation.

Martino, Josephine. 1982. The phoneme $/ \theta /$ and its alternative realization as $/ \mathrm{f} /$ : a study of variation in Australian English among primary school boys, according to socio-economic background. Working Papers in Linguistics 8. 39-42.

Milroy, Lesley. 1987. Language and social networks. Oxford: Blackwell.

Nardy, Aurélie. 2008. Acquisition des variables sociolinguistiques entre 2 et 6 ans: facteurs sociologiques et influences des interactions au sein du réseau social. Grenoble: Université Stendhal Ph.D. dissertation.

Patterson, Janet Lee. 1992. The development of sociolinguistic phonological variation patterns for (ing) in young children. Albuquerque: University of New Mexico Ph.D. dissertation.

Pierrehumbert, Janet. 2001. Exemplar dynamics: word frequency, lenition, and contrast. In J. Bybee \& P. Hopper (eds.), Frequency effects and the emergence of linguistic structure, 137157. Amsterdam: John Benjamins.

Pierrehumbert, Janet. 2002. Word-specific phonetics. In N. Warner \& C. Gussenhoven (eds.), Laboratory Phonology VII, 101-139. Berlin: Mouton de Gruyter.

Pierrehumbert, Janet. 2003. Phonetic diversity, statistical learning, and acquisition of phonology. Language and Speech 46(2-3). 115-154.

Pierrehumbert, Janet. 2006. The next toolkit. Journal of Phonetics 34(4). 516-530.

Reid, Euan. 1978. Social and stylistic variation in the speech of children: some evidence from Edinburgh. In P. Trudgill (ed.), Sociolinguistic patterns in British English, 158-171. London: Edward Arnold. 
Roberts, Julie. 1994. Acquisition of variable rules: (-t,d) deletion and (ing) production in preschool children. Philadelphia: University of Pennsylvania Ph.D. dissertation.

Roberts, Julie. 1997. Acquisition of variable rules: a study of (-t, d) deletion in preschool children. Journal of Child Language 24(2). 351-372.

Roberts, Julie. 2005. Acquisition of sociolinguistic variation. In Martin J. Ball (ed.), Clinical Sociolinguistics, 153-164. Oxford: Blackwell.

Romaine, Suzanne. 1984. The language of children and adolescents: the acquisition of communicative competence. Oxford: Blackwell.

Santos, Antonio J., Brian E. Vaughn \& Jérôme Bonnet. 2000. L'influence du réseau affiliatif sur la répartition de l'attention sociale chez l'enfant en groupe préscolaire. Revue des sciences de l'éducation XXVI(1). 17-34.

Slosberg-Andersen, Elaine. 1990. Speaking with style: the socio-linguistic skills of children. London: Routledge.

Smith, Jennifer, Mercedes Durham \& Liane Fortune. 2007. 'Mam, my trousers is fa'in doon!': community, caregiver and child in the acquisition of variation in a Scottish dialect. Language Variation and Change 19(1). 63-99.

Smith, Jennifer, Mercedes Durham \& Hazel Richards. This issue. The acquisition of stereotypes, indicators and markers in Scottish dialect.

Squires, Lauren M. 2011. Sociolinguistic priming and the perception of agreement variation: testing predictions of exemplar-theoretic grammar. Ann Arbor, MI: University of Michigan Ph.D. dissertation.

Staum Casasanto, Laura. 2009. Experimental investigations of sociolinguistic knowledge. Stanford, CA: Stanford University Ph.D. dissertation.

Tomasello, Michaël. 2003. Constructing a language: a usage-based theory of language acquisition. Cambridge: Harvard University Press.

Tomasello, Michaël. 2006. Acquiring linguistic constructions. In Deanna Kuhn \& Robert S. Siegler (eds.), Handbook of child psychology: vol. 2. Cognition, perception, and language, $6^{\text {th }}$ edn. 255-298. New York: Wiley.

Trudgill, Peter. 1974. The social differentiation of English in Norwich. Cambridge: Cambridge University Press.

Trudgill, Peter. 1975. Sex, covert prestige and linguistic change in the urban British English of Norwich. In Barrie Thorne \& Nancy Henley (eds.), Language and sex: difference and dominance, 88-104. Rowley: Newbury House Publishers.

Williams, Frederick \& Rita C. Naremore. 1969. On the functional analysis of social class differences in modes of speech. Speech Monographs 36. 77-102.

Wolfram, Walt. 1969. A sociolinguistic description of Detroit Negro speech. Washington DC: Center for Applied Linguistics.

Wolfram, Walt. 1989. Structural variability in phonological development: final nasals in Vernacular Black English. In Ralph W. Fasold \& Deborah Schiffrin (eds.), Language change and variation, 301-332. Amsterdam, Philadelphia: John Benjamins.

Youssef, Valérie. 1991. Variation as a feature of language acquisition in the Trinidad context. Language Variation and Change 3(1). 75-101. 